\title{
IoT - Tool of Society 4.0 - Literary Review
}

\author{
Marie Černá ${ }^{1, *}$ and Lucie Vallišová ${ }^{2}$ \\ ${ }^{1}$ University of West Bohemia, Faculty of Economics, Univerzitní 8, 30100 Plzeň \\ ${ }^{2}$ University of West Bohemia, Faculty of Economics, Univerzitní 8, 30100 Plzeň
}

\begin{abstract}
Society 4.0 and its tools influence significantly current human activities. Approach of people to use of information have changed, information technologies became part of our daily life. Data are shared and processed using different processing procedures than were used 20 years ago. It has many impacts on lives of individuals and interpersonal relations. This contribution deals with the issue of Internet of Things (IoT) as the tool enabling people more efficient information management. The objective of this contribution is to outline the significance of IoT and provide the overview of this technology. The contribution is based on the literature research and contains bibliometric analysis confirming the IoT significance for current and future human activities.
\end{abstract}

Keywords: automation, data sharing, digitization, Industry 4.0, IoT, Society 4.0

\section{Introduction}

Current era is typical by constant changes of practices established in all areas of human activity. It is closely associated with rapid development of many scientific areas and tools used by them. The most visible changes caused by such development has occurred in the field of information technologies. Information technologies represent one of the basic preconditions for the human society development. This can be documented by the following table showing the stages of society development defined by Roser [1], Veza, Mladineo, Peko [2] and Schwab [3], Table 1.

\footnotetext{
* Corresponding author: macerna@kfu.zcu.cz
} 
Table 1. Four stages of the industrial revolutions

\begin{tabular}{|c|c|c|c|}
\hline No. & Period & Classification & Brief description \\
\hline 1. & $18^{\text {th }}$ century & $\begin{array}{c}\text { The first } \\
\text { industrial revolution }\end{array}$ & $\begin{array}{c}\text { Mechanization, water } \\
\text { (use of water power), steam. }\end{array}$ \\
\hline 2. & $19^{\text {th }}$ century & $\begin{array}{c}\text { The second } \\
\text { industrial revolution }\end{array}$ & $\begin{array}{l}\text { Mass production, assembly lines, } \\
\text { use of electricity. }\end{array}$ \\
\hline 3. & $2^{\text {nd }}$ half of the $20^{\text {th }}$ century & $\begin{array}{c}\text { The third } \\
\text { industrial revolution }\end{array}$ & Use of computers and automation. \\
\hline 4. & 2011 (resp. 2013) & $\begin{array}{l}\text { The fourth } \\
\text { industrial revolution }\end{array}$ & $\begin{array}{c}\text { Information systems } \\
\text { (digitization, advanced automation, } \\
\text { cognitive technologies, } \\
\text { high-capacity networks). }\end{array}$ \\
\hline
\end{tabular}

Source: Own processing based on [1], 2020.

Currently used concept of bringing new technology, influencing work and way of human behaviour itself, is called Society 4.0 - Industry 4.0.

The fourth industrial revolution is currently accepted as the concept of bringing technology (internet of Things - IoT, robotics, virtual reality, cyber-physical systems, artificial intelligence, big data) influencing significantly work and life generally. Original concept of Industry 4.0 was related to the production area. What comes out, was the fact that this concept will influence the overall design of today's society, therefore the designation of this era was widened. Currently are used terms Industry 4.0 and Society 4.0.

Individuals start to come to terms with the need to use new or improved tools to ensure smooth running of individual work activities. New conditions represent for people challenge and shift to greater efficiency in its actions (time optimization of performed activities). On the other hand, it is simultaneously seen as limitation [4] and people are dealing with the question: 'What is really important in real life?'

Those important things should be ensured by the use of tools provided by Society 4.0. Tools of Society 4.0 that can be used during optimization of business activities (activities ensured by the corporation) are summarized in the following tables, Table $2 \mathrm{a}$ and Table $2 \mathrm{~b}$. 
Table 2a. Tools of Society 4.0 that can be used to optimize the business activities (A-P)

\begin{tabular}{|c|c|c|c|c|}
\hline Tool & Abbreviation & $\begin{array}{c}\text { Use of tool } \\
\text { (selected options) }\end{array}$ & Positives & Negatives \\
\hline $\begin{array}{l}\text { Artificial } \\
\text { Intelligence }\end{array}$ & AI & \begin{tabular}{|ll}
$\checkmark$ & Predictive \\
& management \\
of inventories \\
$\checkmark$ & (ERP systems). \\
$\checkmark$ & Predictive \\
& maintenance. \\
$\checkmark$ & New business \\
& models \\
development.
\end{tabular} & $\begin{array}{ll}\checkmark & \text { Automation. } \\
\checkmark & \text { Focus } \\
& \text { on higher } \\
& \text { value added } \\
& \text { cases solving. } \\
\checkmark & \text { Lack } \\
& \text { of workforce } \\
& \text { solving. } \\
\checkmark & \begin{array}{l}\text { Acceleration } \\
\text { of activities. }\end{array}\end{array}$ & $\begin{array}{ll}\checkmark & \begin{array}{l}\text { Financial } \\
\text { demands }\end{array} \\
\checkmark & \text { of research. } \\
& \text { Misuse } \\
& \text { of research } \\
\text { results. } & \\
\checkmark & \text { The need for } \\
\text { reorganization } & \text { of business } \\
\text { activities. }\end{array}$ \\
\hline Blockchain & & \begin{tabular}{|l}
$\checkmark \quad$ Reliable and \\
anonymized \\
transaction \\
recording and \\
verification.
\end{tabular} & $\begin{aligned} & \checkmark \text { Use in logistic } \\
& \text { chains. } \\
& \checkmark \text { Protected } \\
& \text { communica- } \\
& \text { tion. }\end{aligned}$ & $\begin{array}{ll}\checkmark & \text { Transmission } \\
& \text { capacity } \\
& \text { and storage } \\
& \text { media } \\
& \text { requirements. } \\
\checkmark & \text { Lack of } \\
& \text { competencies. }\end{array}$ \\
\hline Drones & & \begin{tabular}{|ll}
$\checkmark$ & Consignment \\
& deliveries. \\
$\checkmark$ & Insurance \\
& claims solving. \\
$\checkmark$ & Real estate \\
& activities. \\
$\checkmark$ & Construction \\
& inspections. \\
$\checkmark$ & Mapping.
\end{tabular} & $\begin{array}{l}\text { Inspection } \\
\text { and mapping } \\
\text { of various } \\
\text { activities. }\end{array}$ & $\begin{array}{ll}\checkmark & \text { Ensuring } \\
& \text { safety. } \\
\checkmark & \text { Regulation } \\
\text { of users. }\end{array}$ \\
\hline $\begin{array}{l}\text { Internet } \\
\text { of Things }\end{array}$ & IoT & $\begin{array}{l}\checkmark \quad \text { Processing } \\
\text { and analysing } \\
\text { data gathered } \\
\text { by sensors. }\end{array}$ & $\begin{array}{cl}\checkmark & \text { Process } \\
& \text { optimization. } \\
\checkmark & \text { Preventive } \\
& \text { maintenance. } \\
\checkmark & \begin{array}{l}\text { Remote } \\
\text { diagnostics }\end{array}\end{array}$ & $\begin{array}{ll}\checkmark & \text { Building } \\
& \text { of sufficient } \\
\text { infrastructure. }\end{array}$ \\
\hline $\begin{array}{l}\text { 3-D printing } \\
\text { Additive } \\
\text { production }\end{array}$ & & $\begin{array}{ll}\checkmark & \text { 3D objects. } \\
\checkmark & \text { Nano- } \\
& \text { technology. }\end{array}$ & $\begin{array}{ll}\checkmark & \text { Production } \\
& \text { anywhere. } \\
\checkmark & \text { Data transfer. } \\
\checkmark & \text { Fast } \\
& \text { prototyping. } \\
\checkmark & \text { Waste-free } \\
& \text { technologies. }\end{array}$ & 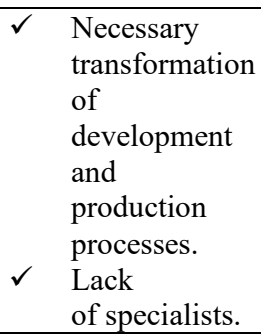 \\
\hline
\end{tabular}

Source: Own processing based on [5], 2020. 
Table 2b. Tools of Society 4.0 that can be used to optimize the business activities (Q-Z)

\begin{tabular}{|c|c|c|c|c|}
\hline Tool & Abbreviation & $\begin{array}{c}\text { Use of tool } \\
\text { (selected options) }\end{array}$ & Positives & Negatives \\
\hline Robotics & & $\begin{array}{ll}\checkmark & \begin{array}{l}\text { Automation } \\
\text { of activities. }\end{array} \\
\checkmark & \text { More } \\
\text { possibilities. }\end{array}$ & $\begin{array}{ll} & \text { Use in health } \\
& \text { care, social } \\
\text { services. } \\
\checkmark & \text { Possibility } \\
\text { to work } 24 \\
\text { hours/week, } \\
\text { no illnesses, } \\
\text { conflicts, etc. }\end{array}$ & $\begin{array}{ll}\checkmark & \text { Initial } \\
& \text { investment. } \\
\checkmark & \text { Staff training. } \\
\checkmark & \text { Socio- } \\
& \text { economic } \\
& \text { consequences. }\end{array}$ \\
\hline $\begin{array}{l}\text { Virtual } \\
\text { and } \\
\text { Augmented } \\
\text { Reality }\end{array}$ & VR, AR & $\begin{array}{ll}\checkmark & \begin{array}{l}\text { Visualization } \\
\text { of industrial }\end{array} \\
& \text { equipment. } \\
\checkmark & \text { Better } \\
& \text { diagnostics. } \\
\checkmark & \text { Navigation, } \\
& \text { easier } \\
& \text { orientation. }\end{array}$ & $\begin{array}{ll}\checkmark & \text { Real time } \\
& \text { operations. } \\
\checkmark & \begin{array}{l}\text { New ways of } \\
\text { carrying out } \\
\text { "experienced" }\end{array} \\
& \text { activities. } \\
\checkmark & \text { Unlimited } \\
& \text { learning } \\
& \text { opportunities. } \\
\checkmark & \text { Greater } \\
& \text { emotional } \\
& \text { experience } \\
\text { for consumer. }\end{array}$ & $\begin{array}{ll}\checkmark & \text { Market } \\
\text { penetration } \\
\text { barriers. } \\
\checkmark & \text { High price. }\end{array}$ \\
\hline
\end{tabular}

Source: Own processing based on [5], 2020.

\subsection{Internet of things (loT)}

IoT (Internet of Things) is often presented as the new paradigm becoming very strong in the field of telecommunication [6], [7]. Basic thought of this concept is pervasive identification of various things or objects using RFID chips, sensors, drivers, mobile phones, etc. [8]. These can communicate and cooperate one with each other, because of the use of unique addressing scheme [9].

Pervasive systems are developed taking into account the necessity to offer open, extensible, evolving portfolio of services integrating sensor data from various sources. It is necessary to ensure suitable and consistent adaptive behaviours during provision of such services even if the huge amount of data gathered by the sensors report different degree of precision, accuracy and dynamism [10].

Internet of things brings together two terms, internet and things. This tool may be accepted as the global network enabling communication between any objects (physical and virtual), between people (human-human), between physical person and thing (humanthing) or between things (thing-thing) [11]. Each object has to be clearly identifiable [12].

IoT does not mean only 'connection', in the sense of connecting electronic facilities as servers, PCs, tablets and smartphones. IoT also means sensors, codes, or embedded systems using the same IP address connecting internet. These networks produce huge amounts of data that have to be further analysed by PCs [13]. If these objects are able to perceive their environment because of their intercommunication abilities, they become 
more or less autonomous tools that can operate largely without human intervention (act without direct supervision of a human) [14].

Internet of Things is taken as the coding and networking of daily used objects to let them become individually machine-readable and traceable using the internet. Future tendencies are to ensure the ability to identify, automate, monitor and control each object [14], [15].

IoT is listed by the US National Intelligence Council as one of the six most important 'disruptive' civil technologies for the potential strengthening of US power [16]. In the following parts of this contribution will be analysed the current level of IoT significance using the bibliometric analysis of this term.

\section{Methodology}

With respect to the set objective of this article '... to outline the significance of IoT and provide the overview of this technology', was conducted bibliometric analysis of the term IoT. The plan of systematic literature review consists of basic steps that the authors followed in preparing this paper as visible in the next table, Table 3.

Table 3. Plan of systematic literary review

\begin{tabular}{|l|l|}
\hline Stage & Description \\
\hline 1 & An overview of publishing activities in a given area by searching for specified phrases. \\
\hline 2 & Application of selection criteria as well as exclusion criteria. \\
\hline 3 & Identification of key terms, authors and journals publishing on this topic. \\
\hline 4 & Conclusions, evaluation. \\
\hline
\end{tabular}

Source: Own processing, 2020.

Authors of this contribution used as the tool quantitative analysis, systematic literary review from the general point of view, focused on selecting basic areas associated with the term IoT and IIoT, as a specific area of IoT. As the database used for the records selection was taken the Scopus database. Within the bibliometric analysis were the terms 'Internet of Things' and 'Industrial Internet of Things' and their abbreviations, 'IoT' and 'IIoT', searched simultaneously using the logical operator AND.

Research took into account headings, key words and also abstracts of the sources. Other precondition set before the research was identification of selected sectors of scientific interest:

- Business, Management and Accounting,

- Social Sciences,

- Engineering,

- Computer Science,

- Economics,

- Econometrics and Finance,

- Decision Sciences.

As the potential sources were used articles published in reviewed professional journals provided in English, without taking into account the place of publication. Next set limitation was the time horizon. Analysed were only publications published since 2000 till 2020. All set criteria are summarized by the following tables, Table 4 and Table 5. 
Table 4. Selection criteria

\begin{tabular}{|l|l|}
\hline Criteria & Explanation \\
\hline Source & Database Scopus. \\
\hline Sectors covered & $\begin{array}{l}\text { Scopus: Business, Management and Accounting; Social Sciences; } \\
\text { Engineering; Computer Science; Economics, Econometrics } \\
\text { and Finance; Decision Sciences. }\end{array}$ \\
\hline Type of studies & Theoretical and empirical character. \\
\hline Language & English. \\
\hline Time period & 2000 - 2020. \\
\hline Type of publication & Magazine articles. \\
\hline Geographical coverage & Worldwide. \\
\hline
\end{tabular}

Source: Own processing, 2020.

Table 5. Exclusion criteria

\begin{tabular}{|l|l|}
\hline Criteria & Explanation \\
\hline Time period before 2000 & $\begin{array}{l}\text { Only a horizon since 2000 has been included. } \\
\text { This is a period of increased interest in this issue. }\end{array}$ \\
\hline Sectors & $\begin{array}{l}\text { Excluded are all other sectors that did not correspond } \\
\text { to the monitored areas. } \\
\text { In these sectors, the occurrence of articles was minimal. }\end{array}$ \\
\hline Language & Much of this issue is discussed in English. \\
\hline Type of publication & Focused on high quality magazine articles. \\
\hline
\end{tabular}

Source: Own processing, 2020. 


\section{Results and discussion}

As the limits of the research can be seen focusing on strictly defined areas of scientific interest. Authors tried to avoid using as the sources those areas of scientific interest where occurrence of the articles dealing with IoT and IIoT is minimal, because of the objective reasons. Therefore, it was decided to take into account the association of IoT with the area dealing with the issue of Industry 4.0. As written above, the twenty-year time horizon was selected. The reason for this represents the fact that the amount of articles dealing with the analysed issue before the year 2000 was very low.

After taking into account all defined prerequisities were, by the Scopus database, searched 4297 records.

If analysing the individual records in time, it is possible to identify significant increase of publications dealing with this issue, since 2015 can be this increase defined as exponential. In 2020 was the amount of selected articles dealing with the analysed issue 1667 . The timeline of the records found in each year can be seen in the following figure, Fig. 1.

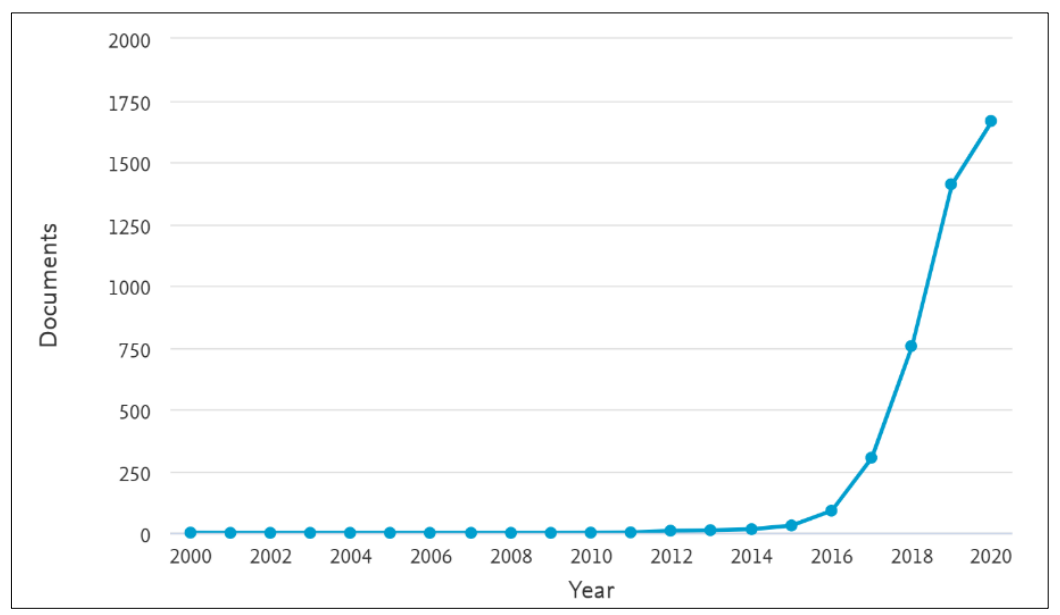

Fig. 1. Number of records found in individual years

Source: Own processing based on [17], 2020.

Increased interest in this issue, visible in Fig. 1, is very likely caused by focusing on simplification of human activities realized by the use of new technologies. Development of these technologies arose as the reaction to turbulent environment and constant changes in current human activities. Technologies belong among the areas of interest of concept Industry 4.0 that is still discussed, even if scientists currently work also with new concepts like Society 5.0 [18] bringing to the previous concept added value in the form of focusing back on people and their needs (even immaterial). This concept takes new technologies more as the tool to reach individual people goals, not as the objective itself. IoT represents one of those upcoming technologies [14]. 
Among the most frequently mentioned keywords in the found articles were the phrases:

- internet of things,

- network security,

- industry 4.0,

- blockchain,

- wireless sensor networks,

- industrial internet of things,

- or cloud computing.

Similarly, the distribution of records by country of origin is not surprising. This topic is most often published in China, followed by the United States and India. Such result fully corresponds to the number of 'Internet users' in each country. The number of found records according to individual territories can be seen in the following figure, Fig. 2.

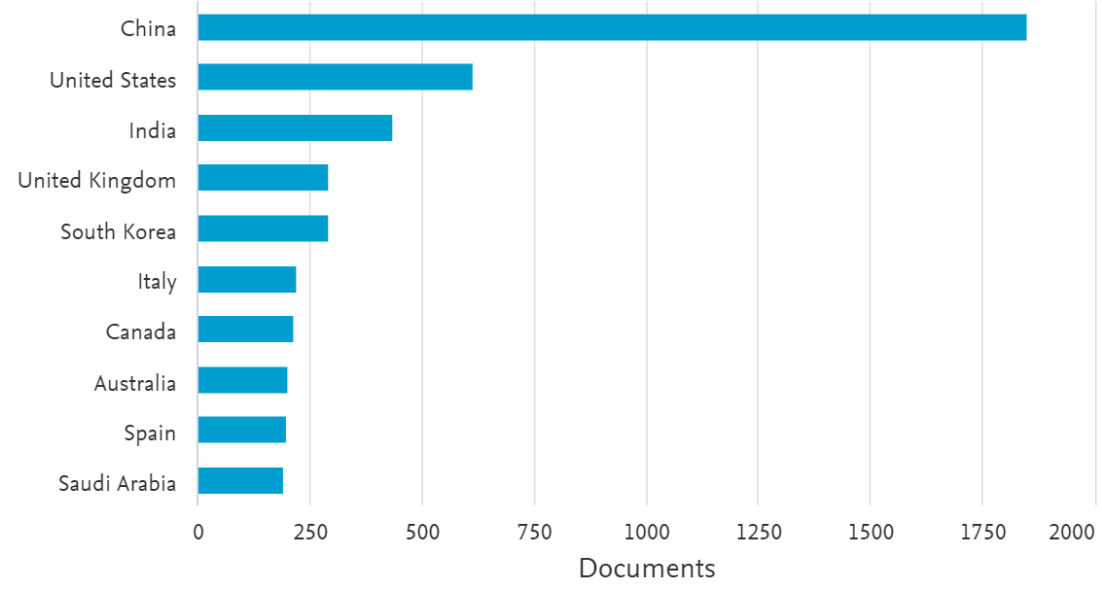

Fig. 2. Number of records found by territory

Source: Own processing based on [17], 2020.

The given phrases appear most often under the heading of the scientific field of computer science (3 095 records) and engineering ( 2822 records). In other areas of scientific interest, the number of records is, compared with the two mentioned fields, much lower.

Set prerequisities can be further discussed, but in this case (compilation of this contribution), represent thoughtful limitations arising from the research objective.

\section{Conclusion}

In conclusion, it can be stated that the bibliometric analysis confirmed the growing interest in the analysed issue. In the period under review, between 2015 and 2020, can be talked about an exponential increase in searching for information dealing with this issue on the Internet.

IoT (or IIoT) belongs to the tools that organizations (and individuals) use to achieve the optimization of business activities. This is one of the most frequently mentioned tools 
of the Society 4.0. In addition to IoT, such tools most often include artificial intelligence, augmented reality, blockchain, drones, robotics, virtual reality, 3D printing and additive manufacturing as mentioned in the first part of this contribution.

All above mentioned tools of Society 4.0 will (already have) have an impact on the changes in standard human activities (labour market, provision of services, care for the elderly people, etc.) and interpersonal relations. It starts to be more visible also thanks to the current global pandemic situation.

'What is really important in real life?' Question asked in the introduction can't be answered easily. It depends on many external factors (political situation, environmental changes, etc.). It is also associated with subjective feeling of each person and perception of values (morality, ethics). Future social and technological changes that will be brought by the current pandemic situation probably more earlier are inevitable. We can just estimate whether or not mankind will use this negative experience (may be opportunity from opposite point of view) to its own welfare.

This contribution was created within the project 'TL02000136 - Knowledge-intensive services sector adaptation to the conditions of Society 4.0', solved by the University of West Bohemia in Pilsen and the Institute of Technology and Business in České Budějovice, with financial support of the Technology Agency of the Czech Republic.

\section{References}

1. Ch. Roser. AllAboutLean. Organize Your Industry [online], Available at: https://www.allaboutlean.com/christoph-roser/ (2020)

2. I. Veza, M. Mladineo, I. Peko, Analysis of the Current state of Croatian Manufacturing Industry with Regard to Industry 4.0. 15 th International Scientific Conference on Production Engineering (CIM 2015), 15 (2015)

3. K. Schwab. The Fourth Industrial Revolution: what it means, how to respond [online], Available at: https://professionallearning.education.gov.scot/media/1352/the-fourthindustrial-revolution-what-it-means-and-how-to-respond-world-economic-forum.pdf (2016)

4. R.H. Weber, Internet of Things - New security and privacy challenges. Computer Law \& Security Review, 26(1), 23-30 (2010)

5. L. Dvořáková et al., Methodics of SMEs enterprises in tertiary sector adaptation on implementation of principles, procedures, methods and tools of Society 4.0. Pilsen: UWB and ITB (2020)

6. A. Saint, Where next for the internet of things? Engineering \& Technology, 10(1), 7275 (2015)

7. H. Tran-Dang, N. Krommenacker, P. Charpentier, D.S. Kim, Toward the Internet of Things for Physical Internet: Perspectives and Challenges. IEEE Internet of Things Journal, 7(6), 1 (2020)

8. D. Miorandi, S. Sicari, F. De Pellegrini, I. Chlamtac, Internet of things: Vision, applications and research challenges. Ad Hoc Networks, 10(7), 1497-1516 (2012)

9. A. Jules, RFID security and privacy: a research survey. IEEE Journal on Selected Areas in Communication, 24(2), 381-394 (2006)

10. J. Ye, S. Dobson, S. McKeever, Situation identification techniques in pervasive computing: A review. Pervasive and Mobile Computing, 8(1), 36-66 (2012) 
11. L. Tan, N. Wang, Future internet: The Internet of Things. ICACTE ( $3^{\text {rd }}$ International Conference on Advanced Computer Theory and Engineering, 3 (2010)

12. R. Aggarwal, M. Las Das, RFID Security in the Context of 'Internet of Things'. First International Conference on security of Internet of Things, 1 (2012)

13. R. Yugha, S. Chitra, A survey on technologies and security protocols: Reference for future generation IoT. Journal of Network and Computer Applications, 169, 1084-8045 (2020)

14. M. Mahbub, Progressive researches on IoT security: An exhaustive analysis from the perspective of protocols, vulnerabilities, and preemptive architectonics. Journal of Network and Computer Applications, 168, 1084-8045 (2020)

15. A. Luigi, I. Antonio, M. Giacomo, The Internet of Things: Survey. Computer Networks, 54(15), 2787-2805 (2010)

16. L. Huichen, N.W. Bergmann, IoT Privacy and Security Challenges for Smart Home Environments. Information, 7(3), 44 (2016)

17. Elsevier B.V. Scopus database [online], Available at: https://www.scopus.com/ (2020)

18. S. Serpa, C. M. Ferreira, Society 5.0 and Sustainability Digital Innovations: A Social Process. Journal of Organizational Culture, Communications and Conflicts, 23(2), 1-14 (2019) 